\title{
Epidemiology and prevention of dental caries ${ }^{*}$
}

\author{
Jolán Bánóczy ${ }^{1}$, Andrew Rugg-Gunn² \\ ${ }^{1}$ Department of Oral Biology, Semmelweis University \\ Budapest, Hungary \\ ${ }^{2}$ School of Dental Sciences, Newcastle University, UK \\ Corresponding author: \\ Jolán Bánóczy \\ Semmelweis University of Medicine \\ Department of Oral Biology \\ Nagyvárad ter 4 \\ 1089 Budapest, Hungary \\ banoczy.jolan@dent.semmelweis-univ.hu \\ Tel.:/Fax.: + 3613032436
}

Received: 8 August 2013; Accepted: 10 August 2013

Copyright (C) 2013 by Academy of Sciences and Arts of Bosnia and Herzegovina. E-mail for permission to publish:amabih@anubih.ba

Dental caries is a chronic disease with low mortality. It is, though, a very common disease, responsible for much suffering, and is one of the most expensive diseases to treat. Within the EU, the cost of dental treatment, most related to dental caries, in 2011 was estimated to be 79 billion euro (1). Dental caries affects all ages; both primary and permanent dentitions. In many European countries, tooth extraction due to dental caries is the commonest reason for general anaesthetics in young children. Yet, it is a preventable disease; its cause is very well known but it is not prevented. Why? Because it is a diet-related lifestyle disease, where prevention requires change to entrenched, and often enjoyable, eating habits. Dental caries was rare before the rise in importation and consumption of sugar. Sugar causes much pleasure but also much disease - and not only dental caries. Strong commercial pressures encourage sugar consumption. However, there are signs that the tide is changing. Medical, dietetic and dental professions now agree on dietary policy. There is much better food labelling now in Europe, with sugars content displayed. In many countries, television advertising of high sugar products cannot be targeted at children, and provision of high sugar foods and drinks is not allowed in schools. Many parents are now well aware of what a healthy diet is and do their best to ensure their children benefit from this knowledge. However, there are many families where life's pressures - financial, availability of time and food choice, and habit - are such that this is not possible. These differences have led to increased social inequality in oral health: the major challenge to those in population oral health. Ironically, it used to be the affluent who had most dental decay; now it is the opposite. This scenario is common to several chronic diseases, often with the same risk factors operating in these several diseases. This requires, what is now well-recognised as the 'common risk

${ }^{*}$ The authors are Professors emeritus, Semmelweis and Newcastle Universities, respectively. No support was provided for the preparation of this paper. 
factor' approach to controlling these costly chronic diseases (2).

Nearly a century ago, classical epidemiology demonstrated the extraordinary ability of fluoride to prevent caries development. By the 1940s, it was clear that the concentration of fluoride naturally present in water was inversely related to the occurrence of dental caries. During the second half of nineteenth century, this property was exploited and many methods developed to ensure that the benefit of fluorides was available as widely as possible. This has radically altered the picture of dental caries both between countries and within countries. In the 1950s and 1960s, dental caries severity was extremely high in northern Europe: now, in younger people, it is low to very low. The present state of dental caries in southern Europe is described in the first article on the prevalence of dental caries in Bosnia and Herzegovina in children and adolescents.

The remarkable decline in caries severity has been due, largely, to widespread use of fluoride. This is well recognised by health authorities and especially by WHO. As an example, at the Sixtieth World Health Assembly in Geneva in May 2007, a Resolution urged Member States to "for those countries without access to optimum levels of fluoride, and which have not yet established systematic fluoridation programmes, to consider the development and implementation of fluoridation programmes, giving priority to equitable strategies such as the automatic administration of fluoride, for example, in drinking water, salt or milk, and to the provision of affordable fluoride toothpaste" (3).

The second article in this Issue discusses possible approaches to prevention. It devotes space to a discussion of nutrition, diet and dental caries, partly because this is the cause of dental caries and partly because this topic is not discussed elsewhere in this Issue. The next four articles are devoted to fluoride and were commissioned by the editors of this
Special Issue. The first three cover the main community, or public health, methods of delivering fluoride - through water, salt and milk. These three methods are often considered the 'automatic' methods of fluoride delivery, in that personal effort is not required by the individual and, in this respect, differs from fluoride toothpaste which is purchased by the individual. Because they are community preventive measures, reaching everyone, they are equitable (thus, reducing inequalities in disease) and economic. The next article discusses the 'home-based' use of fluoride, namely in toothpastes and mouthrinses. All of these articles emphasise that the methods described - automatic, home-care, and professional-care delivery are not alternatives, in competition with each other. On the contrary, fluoride toothpastes should be used in areas where drinking water contains the optimum concentration of fluoride - it safe to do so and it will bring added benefit. The many systematic reviews mentioned in these articles indicate the considerable knowledge base now available to ensure appropriate advice to optimise the benefits of fluoride.

The next article by Croatian pharmacological experts describes the cariostatic mechanisms of fluoride action, explaining the systemic and topical effects of fluoride on oral micro-organisms and on the teeth. A Hungarian paper discusses amine fluorides, describing several studies, and reports on excellent results with topical application of amine-fluoride-containing toothpastes and rinses on caries-risk groups in that country.

The assessment of caries risk is an important topic if prevention is to be targeted at those in greatest need, and authors from Bosnia and Herzegovina investigated the efficiency of a multifactorial model in assisting caries prediction. This is followed by a report on the caries-preventive behaviour and oral health attitudes of Czech parents with regard to their pre-school children. 
Secondary prevention is important too, and the subject of incipient caries is reported in a Croatian paper concerning current possibilities in occlusal caries management and, from Turkey, a study of the effects of pre-treatment of the enamel surface on success in sealing fissures in tooth surfaces. A Bulgarian paper deals with the development of dental practices in Bulgaria during the last twenty years.

Summarizing, this Special Issue on caries epidemiology and prevention, gives an overview on the different methods of caries prevention and control, from about 10 different countries. The use of fluoride is discussed in greater detail because of its major role in caries prevention. We hope that the infor- mation given will stimulate greater effort by all in health care to reduce, if not eliminate, the scourge of oral disease.

Conflict of interest: The authors are Trustees of the Borrow Foundation.

\section{References}

1. Patel R. The state of oral health in Europe. Report commissioned by the Platform for Better Oral Health in Europe; 2012 [cited 2013 Jul 31]. Available from: http:// www.oralhealthplatform. $\mathrm{eu} /$ sites/default/files/field/document/Report - the State of Oral Health in Europe.pdf.

2. Rugg-Gunn AJ. Preventing the preventable - the enigma of dental caries. Br Dent J. 2001;191:478-88.

3. Petersen PE. World health Organization global policy for improvement of oral health - World Health Assembly 2007. Int Dent J. 2008;58:115-21. 